\title{
Learning curve of trans-sacral epiduroscopic laser decompression in herniated lumbar disc disease
}

\author{
Seong Son, Chan Jong Yoo*, Byung Rhae Yoo, Woo Seok Kim and Tae Seok Jeong
}

\begin{abstract}
Background: Trans-sacral epiduroscopic laser decompression (SELD) using slender epiduroscope and a holmium YAG laser is one of the minimally invasive surgical options for lumbar disc herniation. However, the learning curve of SELD and the effect of surgical proficiency on clinical outcome have not yet been established. We investigated patients with lumbar disc herniation undergoing SELD to report the clinical outcome and learning curve.

Methods: Retrospective analysis of clinical outcome and learning curve were performed at a single center from clinical data collected from November 2015 to November 2018. A total of 82 patients who underwent single-level SELD for lumbar disc herniation with a minimum follow-up of 6.0 months were enrolled. Based on the findings that the cut-off of familiarity was 20 cases according to the cumulative study of operation time, patients were allocated to two groups: early group $(n=20)$ and late group $(n=62)$. The surgical, clinical, and radiological outcomes were retrospectively evaluated between the two groups to analyze the learning curve of SELD.
\end{abstract}

Results: According to linear and log regression analyses, the operation time was obtained by the formula: operation time $=58.825-(0.181 \times$ [case number] $)(p<0.001)$. The mean operation time was significantly different between the two groups (mean 56.95 min; 95\% confidence interval [Cl], 49.12-64.78 in the early group versus mean 45.34 min; $95 \% \mathrm{Cl}, 42.45-48.22$ in the late group; $p=0.008$, non-parametric Mann-Whitney $\mathrm{U}$ test). Baseline characteristics, including demographic data, clinical factors, and findings of preoperative magnetic resonance imaging, did not differ between the two groups. Also, there was no significant difference in terms of surgical outcomes, including complication and failure rates, as well as clinical and radiological outcomes between the two groups.

Conclusion: The learning curve of SELD was not as steep as that of other minimally invasive spinal surgery techniques, and the experience of surgery was not an influencing factor for outcome variation.

Keywords: Learning curve, Disc, Lumbar spine, Trans-sacral epiduroscopic laser decompression, Minimally invasive surgery

\section{Background}

Lumbar epiduroscopy, also known as lumbar epidural endoscopy, is a minimally invasive percutaneous procedure to assess the epidural space thorough the sacral

\footnotetext{
*Correspondence: nschan@gilhospital.com

Department of Neurosurgery, Gil Medical Center, Gachon University College of Medicine, \#24, 74th Street, Namdongdaero Namdong-Gu, Incheon 405-220, South Korea
}

hiatus. Trans-sacral epiduroscopic decompression (SELD), involving the use of a small-caliber flexible epiduroscope and laser technology, was developed in early 2000s [1]. SELD has been clinically used in lumbosacral spine diseases for direct visual diagnosis and treatment of epidural pathology, including disc herniation, spinal stenosis, and epidural space adhesion [2-7].

Recently, based on the principle of lasers to condense the hydrated herniated disc, mild to moderate soft disc 
herniation is considered as the optimal indication of SELD $[8,9]$. Accordingly, several previous studies have reported its various clinical outcome and safety in lumbar disc herniation [8-11]. In addition, SELD is considered to be an easier procedure than classical full endoscopic spinal surgery [8]. However, there is a definite threshold for a skillful surgical technique in terms of the approach via the sacral hiatus, safe entering into the ventral epidural space, reaching the target site by a flexible endoscope, and utilizing a very narrow and magnified endoscopic view. Accordingly, we assumed that the learning curve of a surgeon to SELD, that is whether the surgeon is a beginner or expert of SELD, might affect the clinical outcome.

However, there are no reports about the learning curve of SELD and the effect of surgical proficiency on clinical outcome. In this paper, we analyzed the learning curve of SELD and evaluated outcomes based on the degree of surgical skill in patients with lumbar disc herniation.

\section{Methods}

\section{Indications and patient population}

As described in author's previous article [9], the indication for SELD was mild to moderate soft disc herniation with concordant low back pain and/or radicular leg pain despite conservative management (medication, physiotherapy, or nerve block) at least 2 weeks or concordant severe pain making daily life activities impossible. The contraindication included disc herniation with motor weakness, calcified disc herniation, inaccessible foraminal disc herniation, spinal stenosis or instability, infection, limited blood coagulation symptom, anomaly of sacral hiatus, or peridural cyst.

Between November 2015 and November 2018, among 116 patients who underwent SELD by one surgeon in a single institution, 82 patients were selected and data analysis was performed retrospectively. To minimize the bias of patient selection, study inclusion criteria were as follows: (1) single-level disc herniation, (2) no history of surgery in the lumbar spine, and (3) at least 6 months of follow-up with complete medical record.

All surgical procedures were performed by one surgeon via sacral hiatus under local anesthesia according to the previously reported methods [9].

\section{Learning curve evaluation based on the operation time}

The authors assessed the learning curve of SELD by analyzing the operation time. The operation time was defined as the duration from the skin incision to skin closure. The authors recorded the operation time according to case number, and linear regression analyses was performed to reveal the linear correlation between operation time and case series number. Furthermore, cumulative analysis of operation time was performed in order to confirm a cut-off value of familiarity.

\section{Outcome evaluation}

We performed retrospective analysis in terms of baseline characteristics, surgical outcome, clinical outcome, and radiological outcome as depicted in author's previous article [9]. Based on the significant cut-off value of operation time according to the cumulative analysis of operation time, the final cohort was divided into two groups: the early group including the earlier 20 cases and the late group including the later 62 cases (Fig. 1).

Demographic data, such as age, sex, body mass index, and clinical baseline characteristics, such as past medical history, preoperative duration of symptom, previous history of nerve block, trauma history, and symptom dominance (low back pain or radiating leg pain) were assessed between the two groups. In addition, preoperative magnetic resonance imaging (MRI) findings, such as degree of disc degeneration and degree of herniation, were evaluated between the two groups. The volume of disc herniation was determined as transverse diameter $\times$ depth $\times$ height of disc herniation $\times 1 / 2 \quad\left(\mathrm{~mm}^{3}\right)$ (Fig. 2).

Surgical outcomes, including complication rate and failure or recurrence rate, were evaluated between the two groups. The failure or recurrence rate was assessed using an additional procedure rate including revision surgery or nerve block during 6 months after surgery.

Clinical outcomes, including visual analogue scale (VAS) scores of low back pain and leg pain, and patient satisfaction using Odom's criteria, were surveyed at each follow-up visits ( 1 week, 1 month, and 6 months after surgery) between the two groups.

Plain radiographs were performed preoperatively and at 6 months, and we analyzed the radiological change in lumbar alignment between the two groups. Segmental angle and range of motion at the surgery level as well as total lumbar lordosis were assessed using Cobb's method (Fig. 3).

\section{Statistical analysis}

Data management and statistical analysis were performed using SPSS version 23.0 (SPSS Inc., Chicago, IL, USA). We performed a cumulative study and linear regression analysis to analyze the learning curve based on operation time. In addition, Pearson's chi square test, non-parametric Mann-Whitney $\mathrm{U}$ test, and independent $\mathrm{t}$-test were used according to the characteristics of the factors to identify differences between the two groups. Results are expressed as means \pm standard deviations or means with 95\% confidence intervals (CIs), and statistical significance was considered for $\mathrm{p}$ values of $<0.05$. 


\section{6 patients underwent SELD between 2015 and 2018}

\section{Excluded patients $(n=34)$}

-15: multi-level SELD

-6: history of previous surgery

-13: insufficient follow-up duration

or incomplete medical record
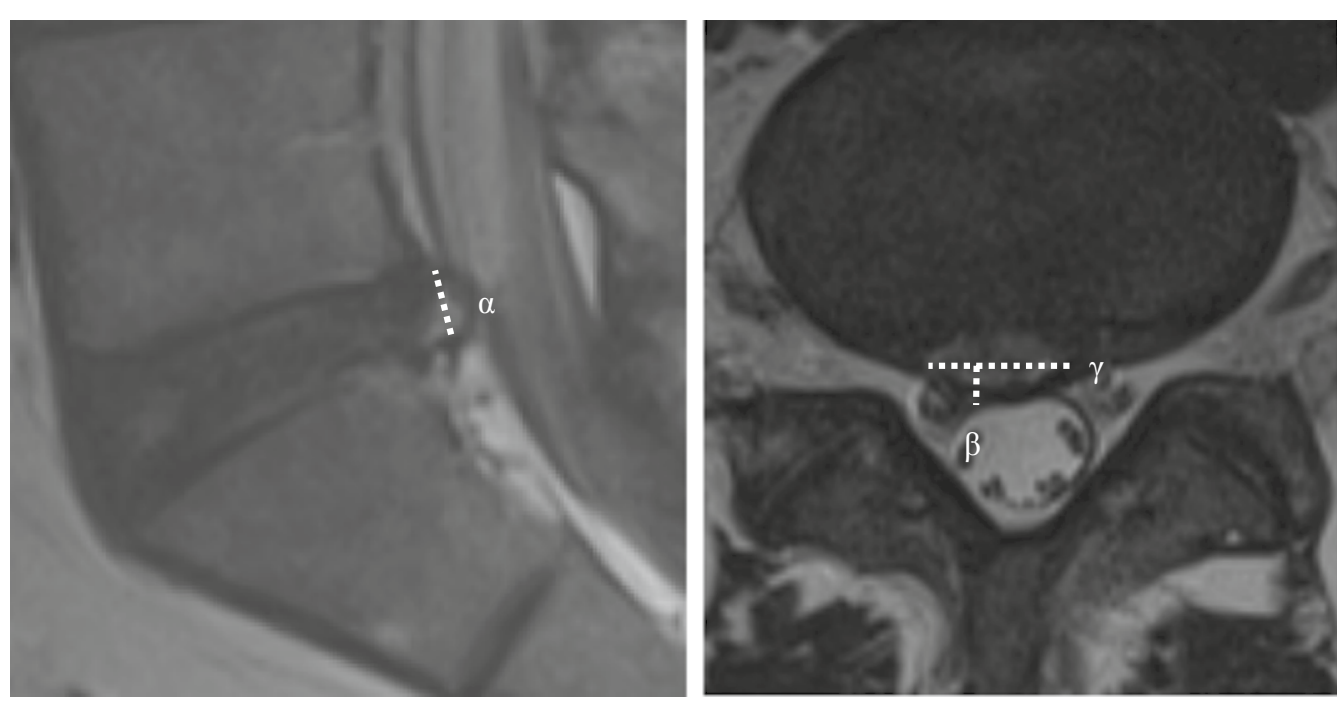

Fig. 2 The protruded disc volume was determined as height $(\mathrm{a}) \times$ depth $(\beta) \times$ transverse diameter $(\gamma)$ of disc herniation $\times 1 / 2\left(\mathrm{~mm}^{3}\right)$ in preoperative magnetic resonance imaging

\section{Results}

Learning curve of SELD based on operation time

The mean operation time was 56.07 (95\% CI, 48.18$63.97)$ minutes among all patients. There was a trend of decreasing operation time with an accumulation of case series or surgical experience of the surgeon (Fig. 4).

According to the cumulative study, the cumulative average operation time appeared to plateau after 20 

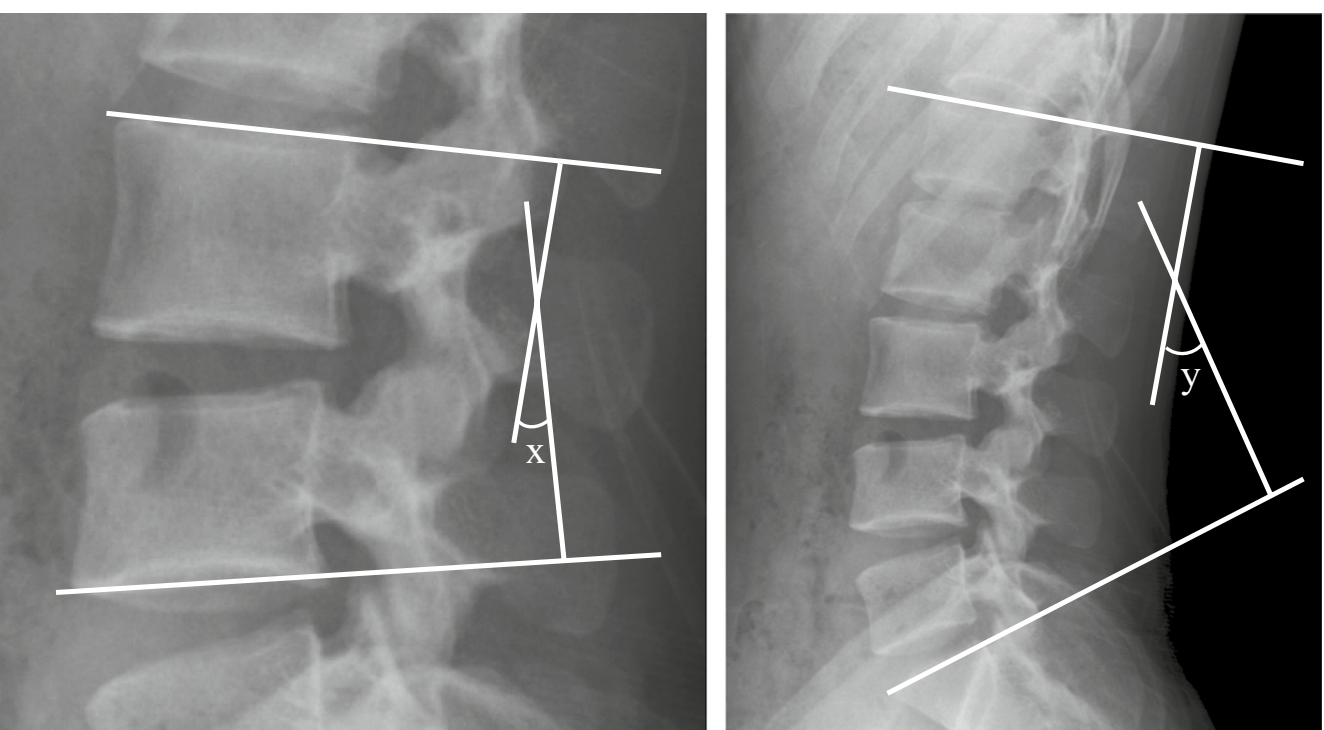

Fig. 3 Lateral plain radiograph of the lumbar spine showing measured variables. Segmental angle $(\mathrm{x})$ and total lumbar lordosis (y) were defined at the intersection of lines

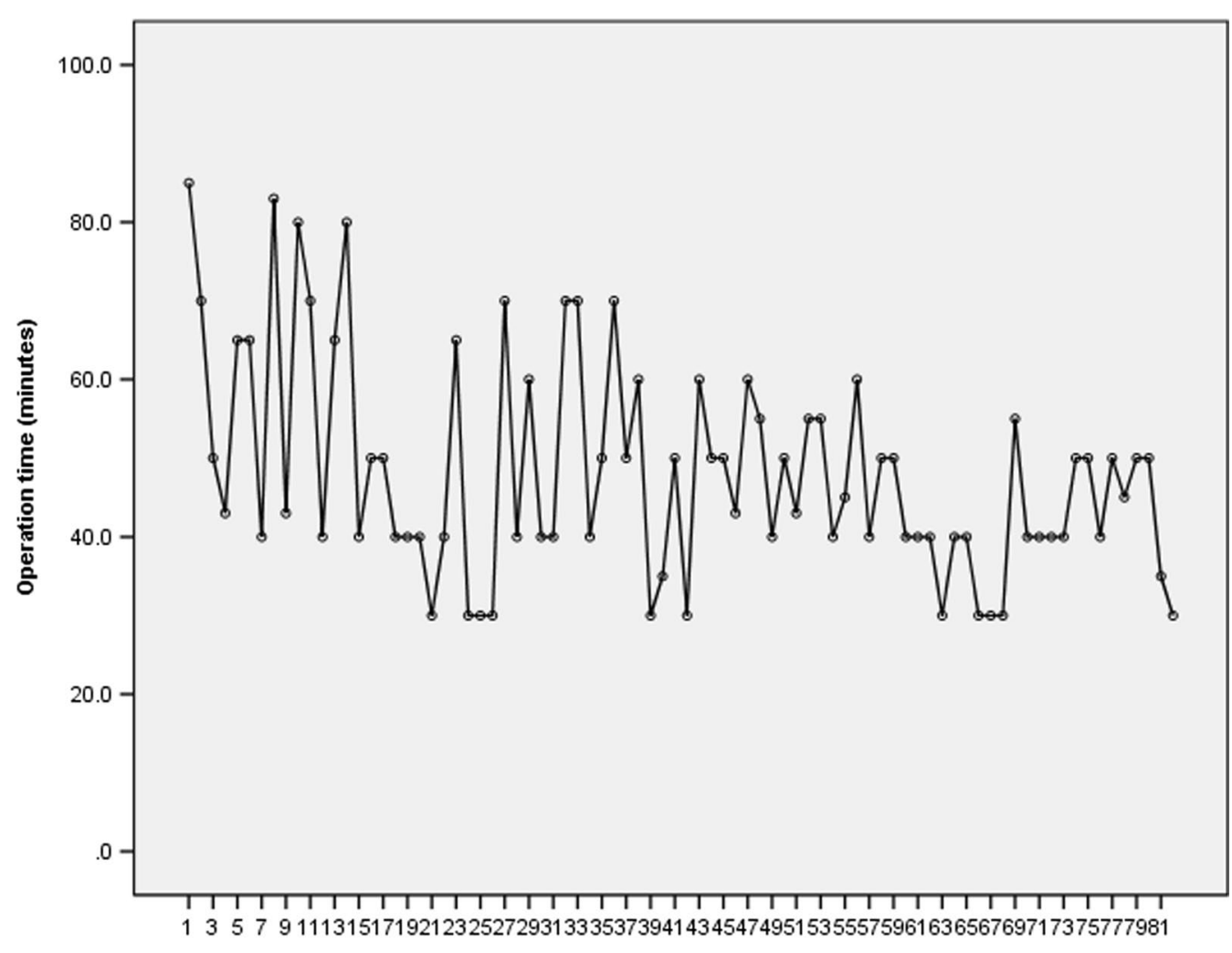

Fig. 4 Operation time according to case series number

Case series 
cases. The mean operation time were most significantly different between the earlier 20 cases and the later 62 cases $(56.95$ [95\% CI, 49.12-64.78] minutes in the early group versus 45.34 [95\% CI, 42.45-48.22] minutes in the late group; $\mathrm{p}=0.008$, non-parametric Mann-Whitney U test) (Fig. 5).

According to linear regression analyses, the operation time was obtained by the formula: operation time $=58.825-(0.181 \times$ case number $]) \quad(\mathrm{p}<0.001)$, suggesting that the operation time was significantly reduced with the accumulation of operations performed. Furthermore, the proportional constant, - 0.181, means that the operation time decreased straightly even in cases where surgeons had limited surgical experience (Fig. 6).

\section{Baseline characteristics between the early and late groups} Demographic data and clinical baseline characteristics were not different between the two groups (Table 1).

Baseline characteristics determined by preoperative MRI and intraoperative findings, also, were not differ significantly between the two groups (Table 2).

\section{Surgical outcome between the early and late groups}

The overall surgical complication rate was $8.5 \%$ and surgical failure or recurrence rate was $17.1 \%$ during 6 months after surgery. Although the operation time was significantly shorter in the late group, the surgical outcomes, including hospital stay, return to work, surgical complication rate, and surgical failure or recurrence rate, were not different. In particular, surgical complication rate $(10.0 \%$ in the early group versus $8.1 \%$ in the late group) and surgical failure or recurrence rate $(15.0 \%$ in the early group versus $17.7 \%$ in the late group) were similar between the two groups (Table 3). Surgical complications in the early group included 1 patient with transient nuchal pain during the procedure and 1 patient with transient motor weakness; whereas, surgical complications in the late group included 3 patients with transient nuchal pain during the procedure, 1 patient with transient motor weakness, and 1 patient with dura puncture during the procedure.

\section{Clinical outcome and radiological outcome between the early and late groups}

The overall patient satisfaction rate was $58.5 \%$ according to Odom's criteria at final follow-up. Clinical outcomes,

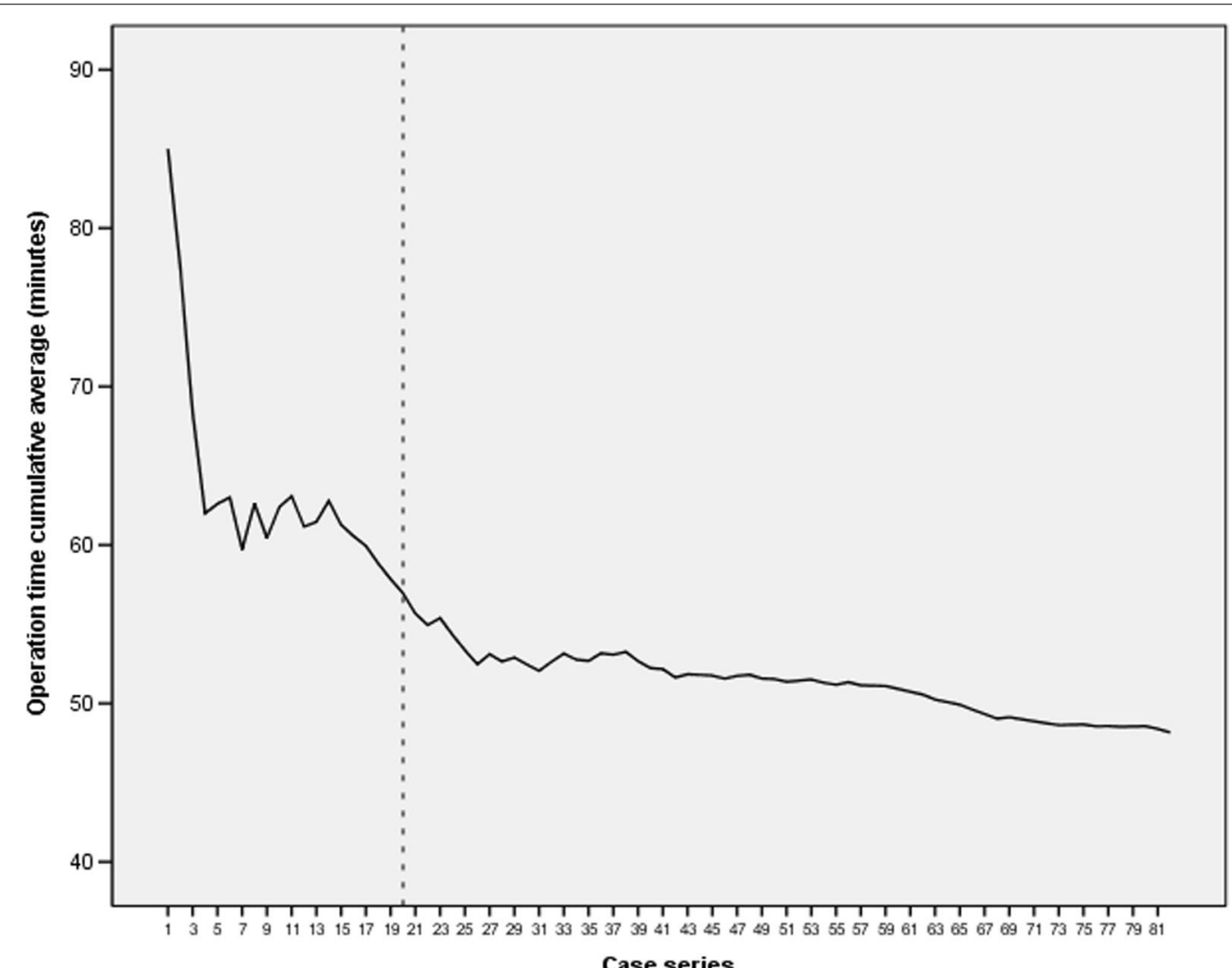

Case series

Fig. 5 Linear and log regression analyses. Operation time $=58.825-(0.181 \times[$ case number $])(p<0.001)$ 


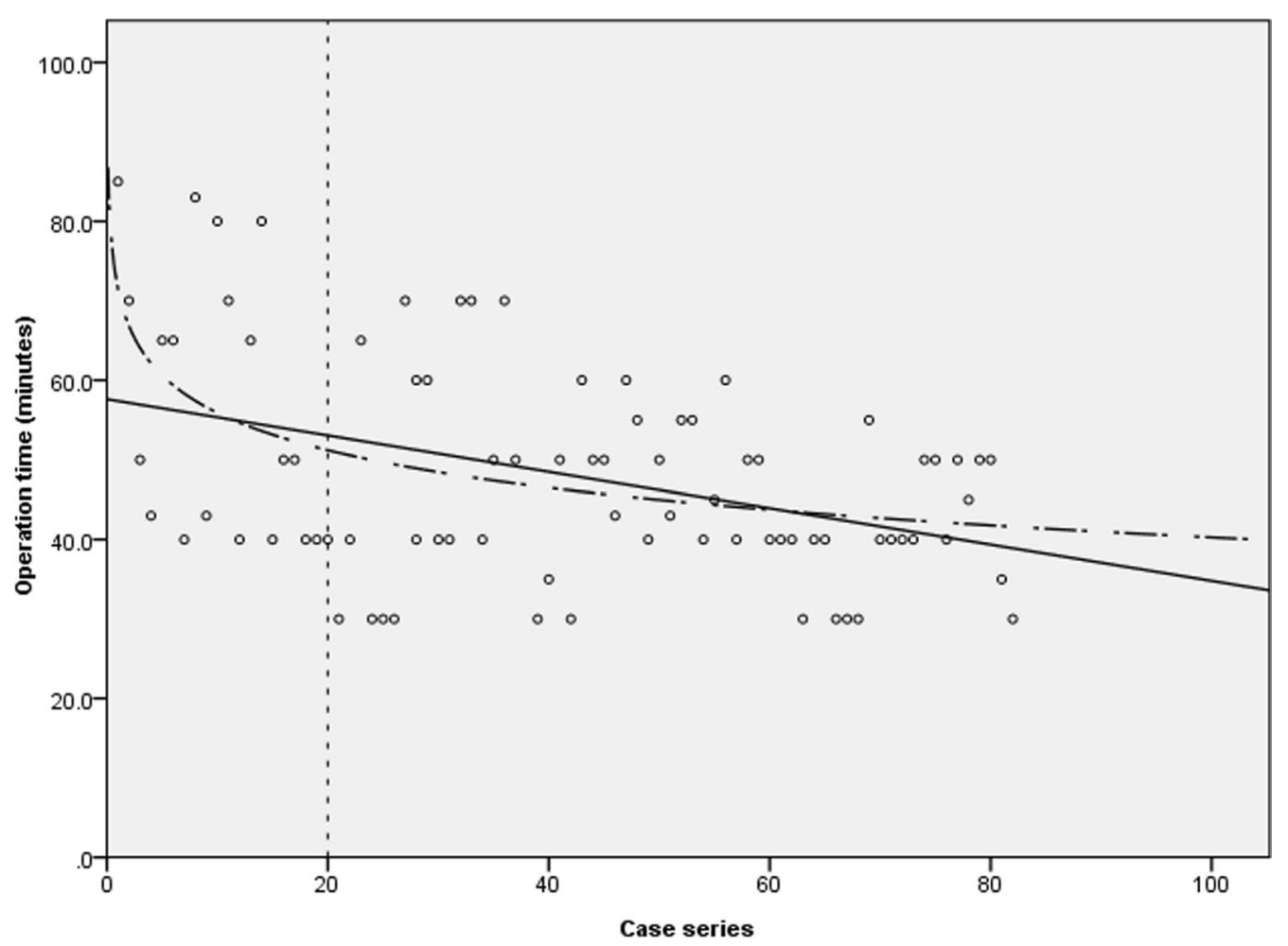

Fig. 6 Cumulative study of the average operation time

Table 1 Demographic data and clinical baseline characteristics between the two groups

\begin{tabular}{|c|c|c|c|c|c|}
\hline & $\begin{array}{l}\text { Early group } \\
(\mathrm{n}=20)\end{array}$ & $\begin{array}{l}\text { Late group } \\
(n=62)\end{array}$ & OR or difference & $95 \% \mathrm{Cl}$ & $P$ value \\
\hline Age & $41.15 \pm 15.44$ & $40.43 \pm 15.43$ & $-0.72 \pm 4.82$ & $-9.030-10.480$ & $0.882^{\dagger}$ \\
\hline Male ratio & $14(70.0 \%)$ & $38(61.3 \%)$ & 1.750 & $0.482-6.351$ & $0.520^{\ddagger}$ \\
\hline Smoking status & $7(35.0 \%)$ & $19(30.6 \%)$ & 0.743 & $0.199-2.779$ & $0.658^{\ddagger}$ \\
\hline Alcohol consumption (g/week) & $0.42(95 \%$ Cl 0.08-0.76) & $0.43(95 \%$ Cl 0.097-0.761) & $0.01 \pm 0.23$ & $-0.469-0.452$ & $0.820^{\S}$ \\
\hline Height $(\mathrm{cm})$ & $170.67 \pm 11.37$ & $168.32 \pm 9.17$ & $2.35 \pm 3.22$ & $-4.163-8.885$ & $0.470^{\dagger}$ \\
\hline Weight (kg) & $68.92 \pm 15.86$ & $70.04 \pm 11.81$ & $1.12 \pm 4.35$ & $-9.926-7.680$ & $0.798^{\dagger}$ \\
\hline Body mass index $\left(\mathrm{kg} / \mathrm{m}^{2}\right)$ & $23.46 \pm 3.72$ & $24.79 \pm 4.22$ & $1.33 \pm 1.25$ & $-3.847-1.191$ & $0.293^{\dagger}$ \\
\hline Diabetes & $1(5.0 \%)$ & $5(8.1 \%)$ & 2.000 & $0.617-23.960$ & $0.578^{\ddagger}$ \\
\hline Hypertension & $3(15.0 \%)$ & $15(24.2 \%)$ & 2.267 & $0.481-10.680$ & $0.294^{\ddagger}$ \\
\hline Previous block & $9(45.0 \%)$ & $39(62.9 \%)$ & 3.056 & $0.838-11.136$ & $0.086^{\ddagger}$ \\
\hline Trauma history & $3(15.0 \%)$ & $9(14.5 \%)$ & 0.944 & $0.167-5.339$ & $0.948^{\ddagger}$ \\
\hline Symptom duration (weeks) & $3.87(95 \%$ Cl 1.84-5.90) & $1.63(95 \%$ Cl $0.67-2.60)$ & $2.24 \pm 1.06$ & $0.949-4.378$ & $0.092^{\S}$ \\
\hline Dominant symptom, back pain/leg pain & $8 / 12$ & $18 / 44$ & 2.133 & $0.556-8.187$ & $0.265^{\ddagger}$ \\
\hline
\end{tabular}

$\mathrm{Cl}$ confidence interval, $\mathrm{OR}$ odds ratio

${ }^{\dagger}$ Independent t-test, ‡Pearson's Chi square test, §Mann-Whitney U test

including VAS for low back pain or leg pain and patient satisfaction according to Odom's criteria, were not significantly different between the two groups (Table 4).

Also, radiological outcomes, including disc height, neutral segmental angle of surgery level, range of motion of surgery level, and total lumbar lordosis, were not significantly different between the two groups at 6 months after surgery (Table 5). 
Table 2 Baseline characteristics determined by preoperative magnetic resonance imaging and intraoperative findings

\begin{tabular}{|c|c|c|c|c|c|}
\hline & $\begin{array}{l}\text { Early group } \\
(\mathrm{n}=20)\end{array}$ & $\begin{array}{l}\text { Late group } \\
(n=62)\end{array}$ & OR or difference & $95 \% \mathrm{Cl}$ & $P$ value \\
\hline Surgical level, L3-4/L4-5/L5-S1 & $2 / 8 / 10$ & $4 / 14 / 44$ & & & $0.111^{\dagger}$ \\
\hline Pfirmann grade, I/II/III/IV & $0 / 4 / 12 / 3$ & 0/18/38/7 & & & $0.763^{\dagger}$ \\
\hline High intensity zone & $6(30.0 \%)$ & $22(35.5 \%)$ & 1.436 & $0.391-5.269$ & $0.585^{\ddagger}$ \\
\hline Morphology of disc, bulging/protruded/extruded & $2 / 11 / 9$ & $8 / 35 / 17$ & & & $0.130^{\dagger}$ \\
\hline Location of herniation, central/right/left & $6 / 7 / 7$ & $20 / 13 / 29$ & & & $0.092^{\dagger}$ \\
\hline Degree of canal compromise, mild/moderate/severe & $13 / 7 / 0$ & $43 / 15 / 0$ & & & $0.208^{\dagger}$ \\
\hline $\begin{array}{l}\text { Degree of nerve compression, abutting/displace/near } \\
\text { obliteration/obliteration }\end{array}$ & $8 / 7 / 4 / 1$ & $34 / 21 / 6 / 1$ & & & $0.264^{\dagger}$ \\
\hline Herniated disc volume $\left(\mathrm{mm}^{3}\right)$ & $0.31 \pm 0.11$ & $0.30 \pm 0.14$ & $0.01 \pm 0.04$ & $-0.08-0.09$ & $0.898^{\ddagger}$ \\
\hline Degree of stenosis, none/mild/moderate/severe & $12 / 7 / 1 / 0$ & $42 / 19 / 1 / 0$ & & & $0.450^{\dagger}$ \\
\hline Intraoperative adhesion, mild/moderate/severe & $2 / 2 / 16$ & $3 / 20 / 29$ & & & $0.249^{\dagger}$ \\
\hline
\end{tabular}

$\mathrm{Cl}$ confidence interval, $\mathrm{OR}$ odds ratio

† Pearson's Chi square test, findependent t-test

Table 3 Surgical outcomes between the two groups

\begin{tabular}{|c|c|c|c|c|c|}
\hline & $\begin{array}{l}\text { Early group } \\
(n=20)\end{array}$ & $\begin{array}{l}\text { Late group } \\
(n=62)\end{array}$ & OR or difference & $95 \% \mathrm{Cl}$ & $P$ value \\
\hline Operation time (min) & $\begin{array}{r}56.95(95 \% \mathrm{Cl} \\
49.12-64.78)\end{array}$ & $\begin{array}{r}45.34(95 \% \mathrm{Cl} \\
42.45-48.22)\end{array}$ & $11.61 \pm 4.01$ & $3.353-19.872$ & $0.008^{\dagger}$ \\
\hline Hospital stay (days) & $3.7 \pm 0.9$ & $3.5 \pm 1.2$ & $0.2 \pm 0.8$ & $-0.749-1.354$ & $0.764^{\ddagger}$ \\
\hline Return-to-work (days) & $15.5 \pm 7.0$ & $15.0 \pm 5.2$ & $0.5 \pm 2.0$ & $-4.429-5.783$ & $0.848^{\ddagger}$ \\
\hline Complication & $2(10.0 \%)$ & $5(8.1 \%)$ & 0.950 & $0.055-16.293$ & $0.744^{\S}$ \\
\hline Failure or recurrence & $3(15.0 \%)$ & $11(17.7 \%)$ & 0.083 & $0.009-0.781$ & $0.904^{\S}$ \\
\hline Additional block & $2(10.0 \%)$ & $6(9.7 \%)$ & 0.947 & $0.120-7.457$ & $0.678^{\S}$ \\
\hline Revision surgery & $1(5.0 \%)$ & $5(8.1 \%)$ & 2.000 & $0.167-23.960$ & $0.578^{\S}$ \\
\hline
\end{tabular}

Cl confidence interval, $O R$ odds ratio

+ Mann-Whitney U test, \#independent t-test, §Pearson's Chi square test

\section{Discussion}

The concept of SELD is an intermediate step between intervention (such as, nerve block or neuroplasty) and surgery (such as, microdiscectomy or full endoscopic surgery). In other words, when nerve block is ineffective or a more effective procedure is needed, but the operation is over-treatment, the SELD can be an option for disc herniation. In terms of this position of SELD, its indication or role is similar with annular modulation or annuloplasty. However, the advantages of SELD includes availability of real endoscopic vision of target lesion, direct ablation of herniated disc, adhesiolysis, and drug injection. In addition, in terms of simple minimally invasive procedure under local anesthesia, the indications of SELD need not to be too heavy like a microdiscectomy or full endoscopic surgery.

According to previous studies, the clinical or surgical outcomes of SELD were found to be favorable in various lumbar spine diseases [3-7, 12-17]. In particular, several recent papers regarding the clinical outcome of SELD for disc herniation have reported that the clinical outcome was favorable as there was significant improvement in low back pain or radiating leg pain, patient satisfaction rate of more than $70 \%$, and low rates of surgical failure or recurrence $[8,18-21]$.

However, according to the result of this study and author's previous report, the clinical outcome was inconsistent with that in previous reports as the patient satisfaction rate was $58.5 \%$ according to Odom's criteria and the surgical failure or recurrence rate was $17.1 \%$ during 6 months of follow-up [9]. This result was not favorable compared to not only previous studies on SELD but also the results of other surgical techniques for lumbar disc herniation [22-24].

After considering the reason for these discordances, we hypothesized that surgeon's learning curve of SELD could affect the outcome. In other words, we speculated that the result may not be favorable in the early stage 
Table 4 Clinical outcomes between the two groups

\begin{tabular}{|c|c|c|c|c|c|}
\hline & $\begin{array}{l}\text { Early group } \\
(\mathrm{n}=20)\end{array}$ & $\begin{array}{l}\text { Late group } \\
(n=62)\end{array}$ & OR or difference & $95 \% \mathrm{Cl}$ & $P$ value \\
\hline \multicolumn{6}{|l|}{ VAS for low back pain } \\
\hline Preoperative & $5.60 \pm 1.82$ & $5.29 \pm 1.68$ & $0.31 \pm 0.546$ & $-0.791-1.422$ & $0.568^{\dagger}$ \\
\hline 1 week & $3.45 \pm 1.79$ & $3.00 \pm 1.00$ & $0.45 \pm 0.45$ & $-0.462-1.366$ & $0.324^{\dagger}$ \\
\hline 1 month & $2.71 \pm 1.40$ & $2.47 \pm 1.74$ & $0.24 \pm 0.54$ & $-0.878-1.342$ & $0.667^{\dagger}$ \\
\hline 6 months & $2.89 \pm 1.69$ & $2.80 \pm 1.32$ & $0.09 \pm 0.62$ & $-1.194-1.371$ & $0.887^{\dagger}$ \\
\hline \multicolumn{6}{|l|}{ VAS for leg pain } \\
\hline Preoperative & $6.15 \pm 1.63$ & $6.05 \pm 1.75$ & $0.10 \pm 0.53$ & $-0.977-1.174$ & $0.847^{\dagger}$ \\
\hline 1 week & $4.00 \pm 1.56$ & $3.81 \pm 2.09$ & $0.019 \pm 0.58$ & $-0.983-1.367$ & $0.743^{\dagger}$ \\
\hline 1 month & $3.53 \pm 2.15$ & $3.18 \pm 2.60$ & $0.35 \pm 0.82$ & $-1.320-2.022$ & $0.670^{\dagger}$ \\
\hline 6 months & $3.56 \pm 1.67$ & $3.60 \pm 2.35$ & $0.04 \pm 0.90$ & $-1.917-1.821$ & $0.961^{\dagger}$ \\
\hline \multicolumn{6}{|l|}{ Odom's criteria } \\
\hline 1 week, Excellent/good/fair/poor & $2 / 11 / 6 / 1$ & $8 / 29 / 24 / 1$ & & & $0.577^{\ddagger}$ \\
\hline 1 month, Excellent/good/fair/poor & $3 / 8 / 9 / 0$ & $17 / 20 / 25 / 0$ & & & $0.383^{\ddagger}$ \\
\hline 6 months, Excellent/good/fair/poor & $2 / 9 / 7 / 2$ & $14 / 23 / 23 / 2$ & & & $0.231^{\ddagger}$ \\
\hline
\end{tabular}

Cl confidence interval, OR odds ratio, VAS visual analog scale

† Independent t-test, $¥$ Pearson's Chi square test

Table 5 Radiological outcomes between the two groups (independent t-test)

\begin{tabular}{|c|c|c|c|c|c|}
\hline & $\begin{array}{l}\text { Early group } \\
(n=20)\end{array}$ & $\begin{array}{l}\text { Late group } \\
(n=62)\end{array}$ & OR or difference & $95 \% \mathrm{Cl}$ & $P$ value \\
\hline \multicolumn{6}{|c|}{ Disc height (mm) } \\
\hline Preoperative & $17.31 \pm 3.74$ & $18.49 \pm 1.85$ & $1.18 \pm 0.89$ & $-2.03-1.93$ & $0.466^{\dagger}$ \\
\hline 6 months & $17.24 \pm 1.65$ & $18.25 \pm 1.42$ & $1.01 \pm 1.55$ & $-2.34-1.91$ & $0.260^{\dagger}$ \\
\hline \multicolumn{6}{|c|}{ Segmental angle $\left({ }^{\circ}\right)$} \\
\hline Preoperative & $7.90 \pm 5.81$ & $8.82 \pm 4.54$ & $0.92 \pm 1.67$ & $-1.32-2.48$ & $0.586^{\dagger}$ \\
\hline 6 months & $7.24 \pm 4.21$ & $8.32 \pm 4.15$ & $1.08 \pm 1.826$ & $-4.88-2.72$ & $0.560^{\dagger}$ \\
\hline \multicolumn{6}{|c|}{ Range of motion $\left({ }^{\circ}\right)$} \\
\hline Preoperative & $4.86 \pm 3.99$ & $6.64 \pm 4.01$ & $1.78 \pm 1.41$ & $-4.63-1.07$ & $0.214^{+}$ \\
\hline 6 months & $3.19 \pm 2.72$ & $5.82 \pm 4.75$ & $2.63 \pm 2.093$ & $-6.90-1.63$ & $0.217^{\dagger}$ \\
\hline \multicolumn{6}{|c|}{ Total lumbar lordosis ( $\left.{ }^{\circ}\right)$} \\
\hline Preoperative & $33.31 \pm 15.95$ & $34.92 \pm 16.05$ & $1.61 \pm 5.22$ & $-12.21-8.98$ & $0.759^{\dagger}$ \\
\hline 6 months & $34.74 \pm 7.35$ & $36.47 \pm 12.40$ & $1.73 \pm 4.81$ & $-11.73-8.26$ & $0.722^{\dagger}$ \\
\hline
\end{tabular}

Cl: Confidence interval, OR: Odds ratio

+ independent t-test

of clinical application compared to that at the adapted stage; as a result, the overall clinical outcome could be unfavorable.

SELD is considerably different from conventional microsurgery or full endoscopic surgery because of the different access route and equipment used. The obstacles in starting SELD include different access methods via the sacral hiatus, unfamiliarity to a steerable guide catheter, difficulty in reaching the target lesion, the use of a very narrow and magnified endoscopic view, the presence of a vague or obscured view owing to epidural bleeding or fat, fear of intradural insertion of a catheter, or uncertainty of successful decompression. The trainee should have worked on at least a certain number of cases to become accustomed to the trans-sacral approach and very narrow two-dimensional steerable endoscopic vision. These barriers may pose challenges for a surgeon at the beginner stage and might result in a steep learning curve and cause unfavorable and inconsistent clinical outcomes.

Operation time is a major parameter to assess the technical proficiency of surgeons [25]. A trend of operation time is an effective statistical tool to assess whether a 
trainee has achieved acceptable proficiency [25]. Surgeon's comfort and technical proficiency is correlated to a decrease in procedure length in chronological case series, and the traditional evaluation of the learning curve has focused on operation time according to the number of cases [26].

In our study, as the number of cases accumulated, the operation time was shortened as a result of familiarity with the surgical technique. The cumulative analysis identified a threshold of 20 cases after which the operation time was consistent. In other words, the operation time approached an asymptote in the 20th case and decreased from a mean $56.95 \mathrm{~min}$ in the initial 20 cases to a mean $45.34 \mathrm{~min}$ in the later 62 cases (decrease of $20 \%)$. On the basis of the asymptote point, we found out that the learning curve of SELD is similar to 10-30 cases of other spinal surgeries, such as microsurgery using tubular retractor or full endoscopic surgery [27-31]. Also, based on the $20 \%$ decrease of operation time and proportional constant of -0.181 in the formula of operation time, the rate of decline is not steep compared to the $23 \%$ to $58 \%$ decrease in operation time during the initial series of cases between the 10th and 30th case of other minimally invasive spinal surgeries [27-31]. These findings imply that the entry barriers for beginners to start SELD are easier or similar compared to those for other techniques.

Another clinically relevant parameter used to assess proficiency of surgeon through the learning curve is the complication or failure rate. Incompetence is inevitable when learning a new surgical technique, particularly minimally invasive surgery; thus, majority of surgery-related complications, failure, or conversions to open techniques usually occurred within the beginner stages of the learning process [26]. The lack of clear anatomic knowledge or orientation and unfamiliarity of new instruments appears to be a significant limitation, and this may cause serious injury to neurologic structures or unintended adverse events in the initial series of patients [32]. Multiple studies on minimally invasive spine surgery have reported that the complication rate is higher and the clinical outcome is poorer at the beginner level than at the expert level [23, 27, 33, 34].

However, in our study, both the clinical outcomes and the surgical outcomes, including complication rate and failure or recurrence rate, were similar between the early and late groups. Based on previous studies, the complication rate of $10 \%$ in the early group was favorable compared to the complication rate of $14-40 \%$ in the novice stage of other minimally invasive spinal surgeries [26, 3537]. Furthermore, the overall incidence of complications was only $8.5 \%$ (7 of 82 patients) and complications were only mild-to-moderate. Among the complications, the transient nuchal pain is related to increase of intracranial pressure due to excessive epidural injection of normal saline for irrigation during surgery. In addition, we speculate that transient motor weakness is related to temporary irritation of nerve root by catheter or laser ablation. These findings suggest that, compared to other minimally invasive spinal surgeries, SELD is relatively easy to learn and is a safe procedure with less complications.

This study has several limitations. Because of its retrospective study design, it was impossible to control for all variations. Moreover, the number of patients in the final cohort was relatively small, and the research was conducted at a single center. However, this single-center study could maintain the quality of follow-up and exclude the factor related to the diversity of surgeons.

To the best of our knowledge, this study is the first to evaluate the learning curve and related outcome of SELD in lumbar disc herniation. More complete studies with a prospective design are required to establish SELD as an easy to learn and safe procedure.

\section{Conclusion}

Based on the operation time and outcomes, the learning curve of SELD was not as difficult as that of other minimally invasive spinal surgeries. According to this result, we believe that SELD is an easy technique to start with safety for novice surgeons. However, further studies are necessary to elucidate the influencing factors on the clinical outcomes of SELD.

\section{Abbreviations}

Cl: Confidence interval; MRI: Magnetic resonance imaging; OR: Odds ratio; SELD: Trans-sacral epiduroscopic laser decompression; VAS: Visual analogue scale.

\section{Acknowledgements}

We would like to thank Editage (www.editage.co.kr) for English language editing.

\section{Authors' contributions}

Dr. SS had full access to all the data in the study and takes responsibility for the integrity of the data and the accuracy of the data analysis. Dr. CJY designed the study protocol. Dr. SS and Dr. BRY managed the literature searches and summaries of previous related work and wrote the first draft of the manuscript. Dr. TSJ and WSK reviewed the contents of this article and devised figure and table. All authors have read and approved the manuscript.

\section{Funding}

There was no external funding.

\section{Availability of data and materials}

The datasets used and analyzed during this study are available from the corresponding author upon reasonable request.

\section{Ethics approval and consent to participate}

The study was approved by the Institutional Review Board of our institute, Gil Medical Center, Gachon University College of Medicine (GAIRB2018-214). The ethics committee waived the requirement for informed consent due to retrospective characteristics of our study and all data were fully anonymized before we accessed them. 


\section{Consent for publication \\ Not applicable.}

\section{Competing interests}

All authors have no conflicts of interest to report. None of the authors of the manuscript received any remuneration. Further, the authors have not received any reimbursement or honorarium in any other manner.

Received: 2 July 2020 Accepted: 5 November 2020 Published online: 18 January 2021

\section{References}

1. Ruetten S, Meyer O, Godolias G. Application of holmium:YAG laser in epiduroscopy: extended practicabilities in the treatment of chronic back pain syndrome. J Clin Laser Med Surg. 2002a;20(4):203-6.

2. Ruetten S, Meyer O, Godolias G. Epiduroscopic diagnosis and treatment of epidural adhesions in chronic back pain syndrome of patients with previous surgical treatment: first results of 31 interventions. Z Orthop Ihre Grenzgeb. 2002b;140(2):171-5.

3. Ruetten S, Meyer O, Godolias G. Endoscopic surgery of the lumbar epidural space (epiduroscopy): results of therapeutic intervention in 93 patients. Minim Invasive Neurosurg. 2003:46(1):1-4.

4. Igarashi T, Hirabayashi Y, Seo N, Saitoh K, Fukuda H, Suzuki H. Lysis of adhesions and epidural injection of steroid/local anaesthetic during epiduroscopy potentially alleviate low back and leg pain in elderly patients with lumbar spinal stenosis. Br J Anaesth. 2004;93(2):181-7.

5. Donato AD, Fontana C, Pinto R, Beltrutti D, Pinto G. The effectiveness of endoscopic epidurolysis in treatment of degenerative chronic low back pain: a prospective analysis and follow-up at 48 months. Acta Neurochir Suppl. 2011;108:67-73.

6. Lee GW, Jang SJ, Kim JD. The efficacy of epiduroscopic neural decompression with Ho:YAG laser ablation in lumbar spinal stenosis. Eur J Orthop Surg Traumatol. 2014;24(Suppl 1):S231-237.

7. Jeon S, Lee GW, Jeon YD, Park IH, Hong J, Kim JD. A preliminary study on surgical navigation for epiduroscopic laser neural decompression. Proc Inst Mech Eng H. 2015;229(10):693-702.

8. Lee SH, Lee SH, Lim KT. Trans-sacral epiduroscopic laser decompression for symptomatic lumbar disc herniation: a preliminary case series. Photomed Laser Surg. 2016;34(3):121-9.

9. Son S, Lee SG, Ahn Y, Kim WK. Clinical outcomes of trans-sacral epiduroscopic laser decompression (SELD) in patients with lumbar disc herniation. Pain Res Manag. 2020;2020:1537875

10. Moon BJ, Yi S, Ha Y, Kim KN, Yoon DH, Shin DA. Clinical efficacy and safety of trans-sacral epiduroscopic laser decompression compared to percutaneous epidural neuroplasty. Pain Res Manag. 2019;2019:2893460.

11. Oh J, Jo D. Epiduroscopic laser neural decompression as a treatment for migrated lumbar disc herniation: case series. Medicine (Baltimore). 2018;97(14):e0291.

12. Dashfield AK, Taylor MB, Cleaver JS, Farrow D. Comparison of caudal steroid epidural with targeted steroid placement during spinal endoscopy for chronic sciatica: a prospective, randomized, double-blind trial. $\mathrm{Br} J$ Anaesth. 2005;94(4):514-9.

13. Jo DH, Yang HJ. The survey of the patient received the epiduroscopic laser neural decompression. Korean J Pain. 2013;26(1):27-31.

14. Jo DH, Yang HJ, Kim JJ. Approach for epiduroscopic laser neural decompression in case of the sacral canal stenosis. Korean J Pain. 2013;26(4):392-5.

15. Jo DH, Kim ED, Oh HJ. The comparison of the result of epiduroscopic laser neural decompression between FBSS or not. Korean J Pain. 2014;27(1):63-7.

16. Kim SK, Lee BH, Song MB, Lee SC. A novel technique for managing symptomatic spinal cysts using epiduroscopic neural laser decompression: technical note and preliminary results. J Orthop Surg Res. 2018;13(1):136.

17. Ceylan A, Asik I, Ozgencil GE, Erken B. Evaluation of the efficacy of epiduroscopic adhesiolysis in failed back surgery syndrome. Turk J Med Sci. 2019:49(1):249-57.
18. Jo D, Lee DJ. The extent of tissue damage in the epidural space by Ho/ YAG laser during epiduroscopic laser neural decompression. Pain Phys. 2016:19(1):E209-214.

19. Hazer DB, Acarbas A, Rosberg HE. The outcome of epiduroscopy treatment in patients with chronic low back pain and radicular pain, operated or non-operated for lumbar disc herniation: a retrospective study in 88 patients. Korean J Pain. 2018;31(2):109-15.

20. Kim SK, Lee SC, Park SW. Trans-sacral epiduroscopic laser decompression versus the microscopic open interlaminar approach for L5-S1 disc herniation. J Spinal Cord Med. 2018. https://doi.org/10.1080/10790 268.2018.1442285.

21. Kim SK, Lee SC, Park SW, Kim ES. Complications of lumbar disc herniations following trans-sacral epiduroscopic lumbar decompression: a singlecenter, retrospective study. J Orthop Surg Res. 2017;12(1):187.

22. Phan K, Xu J, Schultz K, Alvi MA, Lu VM, Kerezoudis P, Maloney PR, Murphy ME, Mobbs RJ, Bydon M. Full-endoscopic versus micro-endoscopic and open discectomy: a systematic review and meta-analysis of outcomes and complications. Clin Neurol Neurosurg. 2017;154:1-12.

23. Choi KC, Lee JH, Kim JS, Sabal LA, Lee S, Kim H, Lee SH. Unsuccessful percutaneous endoscopic lumbar discectomy: a single-center experience of 10,228 cases. Neurosurgery. 2015;76(4):372-80 ((discussion 380-371; quiz 381)).

24. Kamper SJ, Ostelo RWJG, Rubinstein SM, Nellensteijn JM, Peul WC, Arts MP, van Tulder MW. Minimally invasive surgery for lumbar disc herniation: a systematic review and meta-analysis. Eur Spine J. 2014;23(5):1021-43.

25. Dagash $\mathrm{H}$, Chowdhury M, Pierro A. When can I be proficient in laparoscopic surgery? A systematic review of the evidence. J Pediatr Surg. 2003;38(5):720-4

26. Sclafani JA, Kim CW. Complications associated with the initial learning curve of minimally invasive spine surgery: a systematic review. Clin Orthop Related Res. 2014;472(6):1711-7.

27. Dhall SS, Wang MY, Mummaneni PV. Clinical and radiographic comparison of mini-open transforaminal lumbar interbody fusion with open transforaminal lumbar interbody fusion in 42 patients with long-term follow-up. J Neurosurg Spine. 2008;9(6):560.

28. McLoughlin GS, Fourney DR. The learning curve of minimally-invasive lumbar microdiscectomy. Can J Neurol Sci. 2008;35(1):75-8.

29. Lee DY, Lee S-H. Learning curve for percutaneous endoscopic lumbar discectomy. Neurol Med Chir. 2008;48(9):383-9.

30. Tan J, Zheng Y, Gong L, Liu X, Li J, Du W. Anterior cervical discectomy and interbody fusion by endoscopic approach: a preliminary report. $J$ Neurosurg Spine. 2008:8(1):17.

31. Scheufler KM, Kirsch E. Percutaneous multilevel decompressive laminectomy, foraminotomy, and instrumented fusion for cervical spondylotic radiculopathy and myelopathy: assessment of feasibility and surgical technique. J Neurosurg Spine. 2007;7(5):514-20.

32. McAfee PC, Phillips FM, Andersson G, Buvenenadran A, Kim CW, Lauryssen C, Isaacs RE, Youssef JA, Brodke DS, Cappuccino A, et al. Minimally invasive spine surgery. Spine (Phila Pa 1976). 2010;35(26 Suppl):S271-273.

33. Rong LM, Xie PG, Shi DH, Dong JW, Liu B, Feng F, Cai DZ. Spinal surgeons' learning curve for lumbar microendoscopic discectomy: a prospective study of our first 50 and latest 10 cases. Chin Med J. 2008;121(21):2148-51.

34. Park Y, Ha JW. Comparison of one-level posterior lumbar interbody fusion performed with a minimally invasive approach or a traditional open approach. Spine. 2007;32(5):537-43.

35. Mathews $\mathrm{HH}$, Long $\mathrm{BH}$. Minimally invasive techniques for the treatment of intervertebral disk herniation. J Am Acad Orthop Surg. 2002;10(2):80-5.

36. Perez-Cruet MJ, Fessler RG, Perin NI. Review: complications of minimally invasive spinal surgery. Neurosurgery. 2002;51(5 Suppl):S26-36.

37. Rodgers WB, Gerber EJ, Patterson J. Intraoperative and early postoperative complications in extreme lateral interbody fusion: an analysis of 600 cases. Spine. 2011;36(1):26-32.

\section{Publisher's Note}

Springer Nature remains neutral with regard to jurisdictional claims in published maps and institutional affiliations. 